\title{
Development of In Vitro Denture Biofilm Models for Halitosis Related Bac- teria and their Application in Testing the Efficacy of Antimicrobial Agents
}

\author{
Tingxi $\mathrm{Wu}^{1}$, Xuesong $\mathrm{He}^{1}$, Hongyang $\mathrm{Lu}^{2}$, David J. Bradshaw ${ }^{3}$, Alyson Axe ${ }^{3}$, Zvi Loewy ${ }^{4}$, \\ Honghu Liu ${ }^{1}$, Wenyuan $\mathrm{Shi}^{1}$ and Renate Lux ${ }^{1, *}$
} ${ }^{I}$ School of Dentistry, University of California Los Angeles, Los Angeles, USA; ${ }^{2}$ West China School of Stomatology, Si-
chuan University, Chengdu, China; ${ }^{3}$ GlaxoSmithKline, Family Oral Health, Weybridge, UK; ${ }^{4}$ Department of Pharma-
ceutical and Biomedical Sciences, Touro College of Pharmacy, New York, NY, USA

\begin{abstract}
Objective: Since dentures can serve as a reservoir for halitosis-causing oral bacteria, halitosis development is a concern for denture wearers. In this study, we surveyed the prevalence of four selected halitosis-related species (Fusobacterium nucleatum, Tannerella forsythia, Veillonella atypica and Klebsiella pneumoniae) in clinical denture plaque samples, and developed denture biofilm models for these species in vitro to facilitate assessment of antimicrobial treatment efficacy. Design: Denture plaque from ten healthy and ten denture stomatitis patients was screened for the presence of aforementioned four species by PCR. Biofilm formation by these halitosis-associated species on the surfaces of denture base resin (DBR) discs was evaluated by crystal violet staining and confocal laser scanning microscopy. The efficacy of denture cleanser treatment on these mono-species biofilms was evaluated by colony counting. Results: $80 \%$ of the subjects in the denture stomatitis group and $60 \%$ in the healthy group contained at least one of the targeted halitosis-related species in their denture plaque. All halitosis species tested were able to form biofilms on DBR disc surfaces to varying degrees. These in vitro mono-species resin biofilm models were used to evaluate the efficacy of denture cleansers, which exhibited differential efficacies. When forming biofilms on resin surfaces, the halitosis-related species displayed enhanced resistance to denture cleansers compared with their planktonic counterparts. Conclusion: The four selected halitosis-related bacterial species examined in this study are present on the majority of dentures. The mono-species biofilm models established on DBR discs for these species are an efficient screening tool for dental product evaluation.
\end{abstract}

Keywords: Antimicrobial treatment, biofilms, denture, halitosis, model.

\section{INTRODUCTION}

Halitosis, also known as oral malodor or bad breath, is foul-smelling breath exhaled from the oral cavity. It affects about one-third of the population and has profound physical, social and psychological impacts on affected individuals [1]. Halitosis is mainly due to the metabolic products of oral bacteria using proteinaceous compounds from saliva, gingival crevicular fluid, and epithelial cells as substrates [1, 2]. Volatile sulfur compounds (VSCs), especially hydrogen sulfide $\left(\mathrm{H}_{2} \mathrm{~S}\right)$, methyl mercaptan $\left(\mathrm{CH}_{3} \mathrm{SH}\right)$, and dimethyl sulfide $\left[\left(\mathrm{CH}_{3}\right)_{2} \mathrm{~S}\right]$ are the major molecules implicated in oral halitosis [3]. In addition to these VSCs, other malodorous molecules including short-chain fatty acids as well as polyamines produced by anaerobic microbes residing on the surface of the tongue and in the periodontal pockets, contribute to halitosis [2].

A variety of oral bacteria have been shown to produce malodorous compounds [3-8]. Tannerella forsythia (formerly Bacteroides forsythus), Fusobacterium nucleatum, Klebsiella pneumoniae, Veillonella atypica, Porphyromonas gingivalis,

\footnotetext{
*Address correspondence to this author at the Section of Oral Biology in the Division of Oral Biology and Medicine, School of Dentistry, University of California Los Angeles, 33-080 CHS, 10833 Le Conte Avenue, Los Angeles, CA, USA, 90095-1668: Tel: +13102065660; Fax: +13107947109; E-mail: rlux@dentistry.ucla.edu
}

Prevotella intermedia, Treponema denticola, Atopobium parvulum and Eubacterium sulci are common species frequently isolated from halitosis patients [3-8]. These malodorous compound-producing bacteria are present at various sites in the oral cavity, particularly on the dorsum of the tongue, saliva, periodontal pockets, dentures, and dental restoration sites.

Recent studies found a strong association between the degree of denture hygiene and halitosis, with higher levels of VSCs detected among denture-wearing subjects, and particularly in elderly individuals wearing dentures overnight and subjects with denture stomatitis [4, 9-11]. Taken together, these findings suggested that halitosis-related oral bacteria might be able to colonize denture surfaces, become residents of the denture plaque microbial communities and thus contribute to denture-associated halitosis. However, very few studies have investigated the colonization and biofilm formation of halitosis-related oral species on denture surfaces. Meanwhile, with the increased demand for dental hygiene products, simple and reproducible denture biofilm models of halitosis-associated oral species are needed to test the effectiveness of these products, particularly denture cleansers, against denture-associated odor-causing bacteria.

In this study, we evaluated the prevalence of the four selected halitosis-related bacterial species in clinical denture plaque samples of denture stomatitis patients and healthy 
subjects. Furthermore, mono-species denture base resin (DBR) biofilm models were developed for these species and used for evaluating the efficacy of denture cleansers.

\section{MATERIALS AND METHODS}

\subsection{Subjects and Sampling}

Two groups of subjects were included in this study and informed consent was obtained prior to the collection of samples. Group 1 contained ten healthy denture wearers (five women and five men; mean age $69.8 \pm 4.7$ years); group 2 included ten denture wearers diagnosed with denture stomatitis (five women and five men; mean age $61.6 \pm 12.0$ years) based on the guideline for denture stomatitis diagnosis [12]. These individuals had not used antibiotics for at least 3 months before sample collection. Subjects had not been treated for any systemic disease nor were they taking any prescription or nonprescription medications.

Subjects were asked to wear dentures for at least $3 \mathrm{hrs}$ before samples were taken. For sample collection, sterile toothpicks (Fisher, USA) were used to scrape the plaque from the surface of the denture that was in contact with the oral mucosa. Collected plaque samples were placed into separate microcentrifuge tubes containing $0.5 \mathrm{ml}$ of $80 \%$ ethanol and stored at $-20^{\circ} \mathrm{C}$ until DNA extraction. The QIAamp DNA Micro Kit (Qiagen, USA) was used to extract DNA from collected plaque samples according to manufacturer's instructions. DNA quality and quantity were checked with a NanoDrop 2000 spectrophotometer (Thermo, USA).

\subsection{Detection of Halitosis-related Species by Polymerase Chain Reaction (PCR)}

PCR was employed to detect the presence of the four selected halitosis-related bacterial species $K$. pneumoniae, $V$. atypica, $T$. forsythia and $F$. nucleatum within the plaque samples. Bacterial species-specific primers were designed based on previous studies [13-15].

For the PCR reactions, $10 \mathrm{ng}$ DNA isolated from plaque samples was used as template in a $25 \mu 1$ reaction mixture containing $1 \mathrm{x}$ PCR buffer, $1.5 \mathrm{mM} \mathrm{MgCl}_{2}, 0.1 \mathrm{mM}$ each of the four dNTPs, 1 unit Taq DNA polymerase (Invitrogen, USA) and $1 \mu \mathrm{M}$ of each primer. The PCR reaction conditions with optimized cycle and annealing temperature for each specific primer sets were as follows: for K. pneumoniae, specific primers Pf (5'-ATT TGA AGA GGT TGC AAA CGA T-3') and Pr2 (5'-CCG AAG ATG TTT CAC TTC TGA TT-3') were used; the reaction conditions were $94^{\circ} \mathrm{C}$ for $10 \mathrm{~min} ; 35$ cycles of $94^{\circ} \mathrm{C}$ for $30 \mathrm{~s}, 57^{\circ} \mathrm{C}$ for $20 \mathrm{~s}$, and $72^{\circ} \mathrm{C}$ for $20 \mathrm{sec}$, and a final extension at $72^{\circ} \mathrm{C}$ for 10 min. For $V$. atypica, specific primer set ATYF (5'- TCT CTT GTT GAA GAA TTA GAA CGC-3') and VR (5'GTGTAACAAGGGAGTACGGACC-3') was used; the PCR conditions were $94^{\circ} \mathrm{C}$ for $15 \mathrm{~min}, 20$ cycles of $92^{\circ} \mathrm{C}$ for 1 $\min , 57^{\circ} \mathrm{C}$ for $1 \mathrm{~min}$, and $72^{\circ} \mathrm{C}$ for $1 \mathrm{~min}$, followed by $5 \mathrm{~min}$ at $72^{\circ} \mathrm{C}$. For $T$. forsythia, specific primers $5^{\prime}-$ GCGTATGTAACCTGCCCGCA-3' and 5'TGCTTCAGTGTCAGTTATACCT- $3^{\prime}$ were used, and the reaction conditions were $94^{\circ} \mathrm{C}$ for $3 \mathrm{~min}, 30$ cycles of $94^{\circ} \mathrm{C}$ for $1 \mathrm{~min}, 58^{\circ} \mathrm{C}$ for $1 \mathrm{~min}$, and $72^{\circ} \mathrm{C}$ for $2 \mathrm{~min}$, followed by $72^{\circ} \mathrm{C}$ for $5 \mathrm{~min}$. For $F$. nucleatum, specific primer set $5^{\prime}-$ AGAGTTTGATCCTGGCTCAG-3' and 5'-GTCATCGTG
CACACAGAATTGCTG -3' was used; the PCR conditions were $94{ }^{\circ} \mathrm{C}$ for $3 \mathrm{~min} ; 23$ cycles of $94^{\circ} \mathrm{C}$ for $1 \mathrm{~min}, 61.5^{\circ} \mathrm{C}$ for $1 \mathrm{~min}$, and $72^{\circ} \mathrm{C}$ for $30 \mathrm{sec}$, and a final extension at $72^{\circ} \mathrm{C}$ for $5 \mathrm{~min}$.

PCR products were analyzed by agarose gel electrophoresis $(1 \% \mathrm{w} / \mathrm{v})$ in $1 \times$ TAE buffer $(40 \mathrm{mM}$ Tris- $\mathrm{HCl}, 1.18 \mathrm{ml}$ acetic acid, 2 mM EDTA, pH 8.0) and a constant voltage of $100 \mathrm{~V}$ was applied. Images were digitally recorded using the Molecular Imager Gel Documentation system (Bio-Rad, USA) to evaluate the presence of the amplified DNA product.

\subsection{Strains and Growth Conditions}

K. pneumoniae IA 565 is a clinical isolate obtained from the University of Iowa Hospitals and Clinics Special Microbiology Laboratory. The strain was grown in LB medium (Tryptone $10 \mathrm{~g} / \mathrm{L}$ Yeast Extract $5 \mathrm{~g} / \mathrm{L} \mathrm{NaCl} 10 \mathrm{~g} / \mathrm{L}$ ) and incubated at $37^{\circ} \mathrm{C}$ in an aerobic incubator on a rotary shaker operating at $200 \mathrm{rpm}$. T. forsythia ATCC 43037, V. atypica PK 1910 and F. nucleatum ATCC 23726 were grown anaerobically overnight at $37^{\circ} \mathrm{C}$ in $\mathrm{TF}$ medium, $\mathrm{TH}$ medium containing $0.06 \%(\mathrm{w} / \mathrm{v})$ lactic acid and Columbia broth (Difco, USA), respectively [16].

\subsection{DBR Discs}

The acrylic DBR discs used in this study were manufactured as previously described [17]. All resin discs were disinfected with $2 \%(\mathrm{v} / \mathrm{v})$ sodium hypochlorite solution (SigmaAldrich, USA) for $10 \mathrm{~min}$ and immersed in sterilized $\mathrm{ddH}_{2} \mathrm{O}$ overnight prior to microbial inoculation.

\subsection{Growth of Biofilms on DBR Disc Surfaces}

Exponentially growing cultures of the four halitosisassociated bacterial species were diluted in their respective culture medium to a final $\mathrm{OD}_{600}$ of 0.1 . Two $\mathrm{ml}$ of the respective diluted cultures of the different species were added to each well of 12-well plates (Thermo, USA) containing a DBR disc with the rough surfaces exposed. Wells with growth medium alone served as controls. Plates containing cultures of $T$. forsythia, $F$. nucleatum, or $V$. atypica were incubated at $37^{\circ} \mathrm{C}$ anaerobically for $24 \mathrm{hrs}$, while cultures of K. pneumoniae were grown aerobically at $37^{\circ} \mathrm{C}$ for $24 \mathrm{hrs}$.

\subsection{Crystal Violet Staining of Biofilms on DBR Disc Sur- faces}

Biofilms formed on the DBR discs were stained with crystal violet as described previously [18]. Briefly, DBR discs were washed twice with phosphate-buffered saline (PBS), air dried for $30 \mathrm{~min}$, and stained with $0.4 \%(\mathrm{w} / \mathrm{v})$ crystal violet in distilled water for $20 \mathrm{~min}$. The stained discs were gently washed three times with sterilized distilled water and air dried for $30 \mathrm{~min}$ before being photographed. Images were taken with a D50 digital camera (Nikon, Japan).

\subsection{Observation of Biofilms with Confocal Laser Scan- ning Microscopy (CLSM)}

Different methods have been used to study biofilm formation including CLSM, AFM [19]. In our study, CLSM has 
been employed to reveal the biofilm structure as well as the cell viability within biofilms. Biofilms grown on the rough surface of the DBR discs were treated with Polident ${ }^{\circledR}$ experimental formula M138-12 (GlaxoSmithKline, UK) or Efferdent ${ }^{\circledR}$ antibacterial denture cleanser (Prestige brands, USA) for 5 min according to manufacturer's recommendations, and untreated controls were stained with $10 \mu \mathrm{M}$ of the cell-permeable fluorescent stain SYTO 59 (labeling of all cells) and $10 \mu \mathrm{M}$ of the cell-impermeable fluorescent stain SYTOX Green (labeling of cells with compromised cell walls only) (Invitrogen, USA) in PBS buffer for $20 \mathrm{~min}$ at room temperature in the dark before visualization [17]. All biofilm images were collected with a Zeiss LSM 5 PASCAL CLSM using LSM 5 PASCAL software (Zeiss, Germany). Excitation at $633 \mathrm{~nm}$ with an argon laser in combination with a $650 \mathrm{~nm}$ band-pass emission filter was used for SYTO 59 fluorescence imaging. SYTOX Green signals were visualized using $488 \mathrm{~nm}$ excitation with a helium-neon laser and a $503-530 \mathrm{~nm}$ band-pass emission filter.

\subsection{Evaluation of the Treatment Efficacy of Denture Cleansers in Planktonic and Biofilm Conditions}

Biofilms grown on DBR discs were washed three times with PBS buffer before treatment. Two different Polident ${ }^{\circledR}$ denture cleansing tablets (commercialized formulation 50767 and the experimental formulation M138-12) (GlaxoSmithKline, UK) and Efferdent ${ }^{\circledR}$ antibacterial denture cleanser (Prestige Brands, USA) were separately dissolved in $150 \mathrm{ml} 40^{\circ} \mathrm{C}$ distilled water according to manufacturer's instructions. Each DBR disc with attached biofilms was immersed in $50 \mathrm{ml}$ of the treatment solution for $5 \mathrm{~min}$ for all three denture cleansers and an additional experiment with a 15 min immersion period for Efferdent ${ }^{\circledR}$ antibacterial denture cleanser was performed to follow manufacturer's recommendations. DBR discs with attached biofilms treated with PBS buffer served as negative control. After treatment, the DBR discs were washed three times with PBS buffer and subjected to mechanical disruption of the attached biofilms, serial dilution and plating as previously described to obtain colony forming unit counts [17].

One $\mathrm{ml}$ of exponentially growing planktonic cultures $\left(\mathrm{OD}_{600}\right.$ of 1) was washed three times with PBS buffer and pelleted by centrifugation at $16,000 \mathrm{xg}$ for $2 \mathrm{~min}$. One tablet each of the three different denture cleansers tested was predissolved in $150 \mathrm{ml} 40^{\circ} \mathrm{C}$ water for $2 \mathrm{~min}$ and $1 \mathrm{ml}$ of the treatment solution was used to resuspend the pelleted cells. After $5 \mathrm{~min}$ or $15 \mathrm{~min}$ (for the additional treatment with Efferdent ${ }^{\mathbb{B}}$ ) of treatment ( 3 or $13 \mathrm{~min}$ incubation with additional 2 min centrifugation at $16,000 \mathrm{xg}$ ), cells were washed three times with PBS buffer prior to being subjected to serial dilution and plating.

Treatment efficacy was evaluated by comparing the surviving colony-forming units (CFU) on LB agar plates (for $K$. pneumoniae), Columbia agar plates supplemented with $5 \%$ sheep blood (Colorado Serum company, USA) (for $F$. nucleatum), TH agar plates supplemented with $0.06 \%$ lactic acid (for V. atypica), and TF agar plates supplemented with $5 \%$ sheep blood (for T. forsythia) with PBS-treated control group.

\section{RESULTS}

\subsection{The Prevalence of Four Halitosis-related Strains in Denture Plaque}

The aforementioned four halitosis-related bacterial species were chosen as targets for PCR screening among 20 clinical denture plaque samples (10 each for healthy and stomatitis subjects). Among the four targeted species, $K$. pneumoniae was only detected in two of the ten subjects in the stomatitis group, while the remaining three species were present in both groups (Table 1). Their prevalence in healthy and denture stomatitis plaque was $60 \%$ and $40 \%$ for $F$. nucleatum, $30 \%$ and $40 \%$ for $T$. forsythia, $30 \%$ and $10 \%$ for $V$. atypica, $0 \%$ and $20 \%$ for $K$. pneumoniae; respectively (Table 1). Furthermore, $80 \%$ of the subjects in the denture stomatitis group and $60 \%$ in the healthy group contained at least one of the targeted halitosis-related species in their denture plaque (Table 1). Due to small sample sizes, Fisherexact chi-square test was used to examine the difference between stomatitis and healthy groups across the speciesspecific primers $(\mathrm{p}=0.39)$.

\subsection{Biofilm Formation of Halitosis-related Oral Bacterial Strains on DBR Discs with Rough Surfaces}

Crystal violet staining revealed that under the conditions described in Materials and Methods, all four species were capable of forming biofilms on these DBR disc surfaces, although to different extents, as manifested by the different intensities of purple staining (Fig. 1). The biofilm architecture of mono-species biofilms and live/dead distribution of the bacteria within the biofilms was further investigated by CLSM.

CLSM analyses disclosed distinct biofilm architectures for each of the halitosis-related strains tested. F. nucleatum ATCC 23726 formed biofilms with a smooth and homogeneous structure almost completely covering the irregular DBR disc surface (Fig. 2A). A similar surface coverage was observed for T. forsythia ATCC 43037; however, the biofilms formed were less dense compared to $F$. nucleatum with great variations in overall thickness (Fig. 2B). Surface coverage by $V$. atypica PK 1910 was incomplete and less compact compared with mono-species biofilms of $F$. nucleatum and T. forsythia (Fig. 2C). Among the bacterial strains tested $K$. pneumoniae IA 565 displayed the least biofilm forming ability. Colonization was limited to thin, "patchlike" structures leaving most of the surface uncovered (Fig. 2D). The majority of the bacteria cells within all monospecies biofilms were alive as indicated by predominantly green fluorescent (live cell staining with SYTO59) and very limited red fluorescent (dead cell staining with SYTOX Green) labeling.

\subsection{Evaluating the Antimicrobial Efficacy of Denture Cleansers Against DBR Disc Surface-associated Biofilms and Planktonic Cells of Halitosis-related Strains}

For a quantitative assessment of treatment efficacy, the DBR disc based biofilm model developed above as well as planktonic cells of $K$. pneumoniae and $F$. nucleatum were subjected to treatment as above and CFU counts were used as a read-out for treatment efficacy. F. nucleatum 
Table 1. The prevalence of halitosis-related species in denture plaque.

(a)

\begin{tabular}{|c|c|c|c|c|c|c|c|c|c|c|c|}
\hline Healthy subjects & $\mathbf{1}$ & $\mathbf{2}$ & $\mathbf{3}$ & $\mathbf{4}$ & $\mathbf{5}$ & $\mathbf{6}$ & $\mathbf{7}$ & $\mathbf{8}$ & $\mathbf{9}$ & $\mathbf{1 0}$ & Percentage \\
\hline \hline F. nucleatum & 1 & 0 & 1 & 1 & 0 & 1 & 0 & 1 & 1 & 0 & $60 \%$ \\
\hline T. forsythia & 0 & 0 & 1 & 0 & 0 & 1 & 0 & 0 & 1 & 0 & $30 \%$ \\
\hline V. atypica & 0 & 0 & 1 & 1 & 0 & 1 & 0 & 0 & 0 & 0 & $30 \%$ \\
\hline K. pneumoniae & 0 & 0 & 0 & 0 & 0 & 0 & 0 & 0 & 0 & 0 & $0 \%$ \\
\hline
\end{tabular}

(b)

\begin{tabular}{|c|c|c|c|c|c|c|c|c|c|c|c|}
\hline Denture stomatitis subjects & $\mathbf{1}$ & $\mathbf{2}$ & $\mathbf{3}$ & $\mathbf{4}$ & $\mathbf{5}$ & $\mathbf{6}$ & $\mathbf{7}$ & $\mathbf{8}$ & $\mathbf{9}$ & $\mathbf{1 0}$ & Percentage \\
\hline \hline F. nucleatum & 0 & 0 & 0 & 0 & 1 & 0 & 1 & 1 & 0 & 1 & $40 \%$ \\
\hline T. forsythia & 0 & 1 & 0 & 1 & 0 & 1 & 1 & 0 & 0 & 0 & $40 \%$ \\
\hline V. atypica & 0 & 0 & 0 & 0 & 1 & 0 & 0 & 0 & 0 & 0 & $10 \%$ \\
\hline K. pneumoniae & 0 & 0 & 0 & 0 & 0 & 0 & 0 & 0 & 1 & 1 & $20 \%$ \\
\hline
\end{tabular}

Samples collected from 10 subjects with and without denture stomatitis were tested by species specific primers. The detection limit of the PCR approach to identify certain species in this study is about 1 to $2 \times 10^{3}$ cells.

A

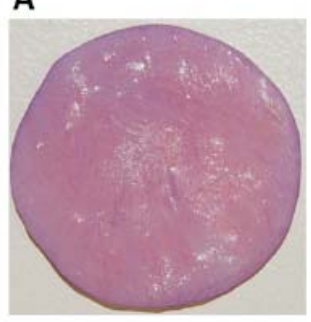

C

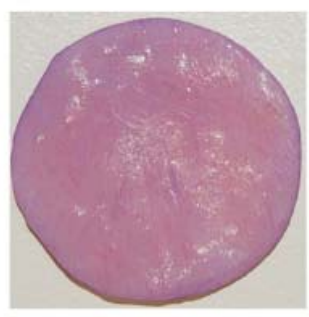

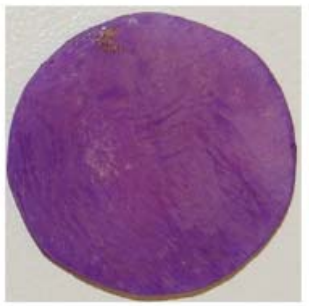

B
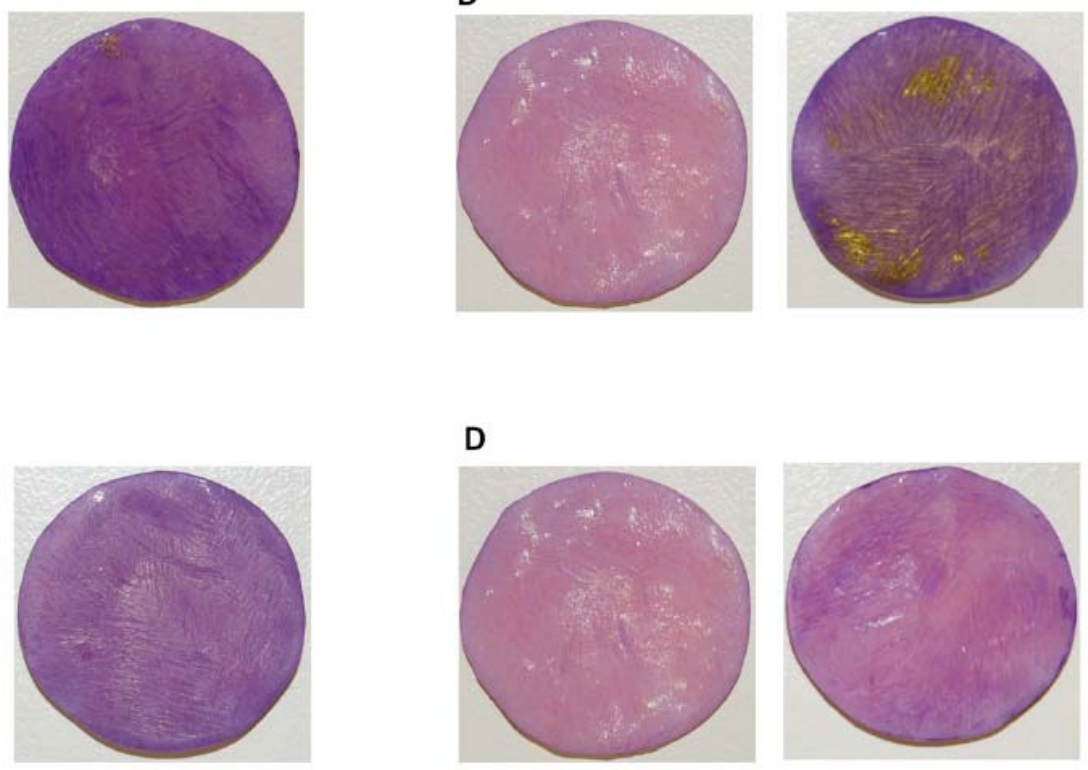

D

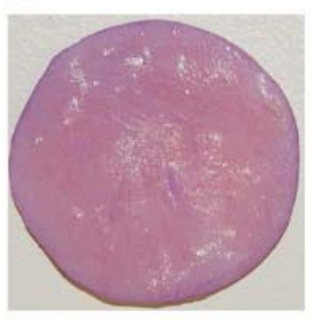

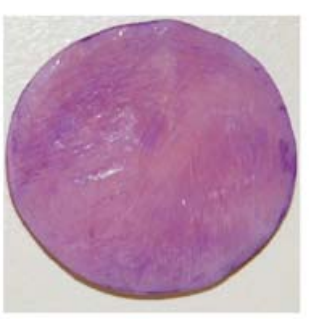

Fig. (1). Biofilm formation on DBR disc surfaces. Representative images after crystal violet staining of biofilms formed on DBR discs by $F$. nucleatum ATCC 23726 (A) T. forsythia ATCC 43037 (B) V. atypica PK 1910 (C) K. pneumoniae IA 565 (D) For each set, the image on the left was a control DBR disc without biofilms growing on the surface, the image on the right was a DBR disc with biofilms growing on the surface. The experiment was performed in triplicate.

mono-species biofilms grown on DBR discs were most sensitive to the experimental formula Polident ${ }^{\circledR}$ M138-12 treatment with no viable cells being detected after 5 min incubation. Treatment with Polident ${ }^{\circledR} 50767$ for the same time period resulted in $10^{2}-10^{3}$ surviving CFU, while $10^{5}-10^{6}$ surviving CFU were still recovered after $5 \mathrm{~min}$ and $15 \mathrm{~min}$ treatment with Efferdent ${ }^{\circledR}$ (Fig. 4A). In contrast, planktonic $F$. nucleatum cells exhibited similar sensitivities to all three formulas, with no surviving CFU being detected after 5 min treatment as well as the additional 15 min treatment with Efferdent $^{\circledR}$ (Fig. 4A). While Polident ${ }^{\circledR} 50767$ and the ex- perimental formula Polident ${ }^{\circledR}$ M138-12 demonstrated similar killing efficacy toward $K$. pneumoniae denture biofilms, resulting in about 4 orders of magnitude reduction (from $\sim 10^{8}$ to $\sim 10^{4}$ ) in cell viability (t-test, $\mathrm{P}<0.01$ ) after $5 \mathrm{~min}$ treatment, Efferdent ${ }^{\circledR}$ manifested about 3 orders of magnitude reduction (from $\sim 10^{8}$ to $\sim 10^{5}$ ) in cell viability (t-test, $\mathrm{P}<0.01$ ) after $5 \mathrm{~min}$ and $15 \mathrm{~min}$ treatment (Fig. 4B). The planktonic form of $K$. pneumoniae was more sensitive than its biofilm counterpart, with no viable cells being detected after a 5 min treatment with Polident ${ }^{\circledR} 50767$ or a 15 min treatment with Efferdent $^{\circledR}$. Three min treatments with the experimental 
A

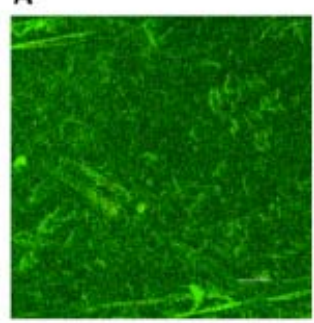

C

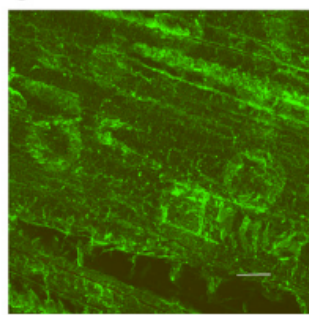

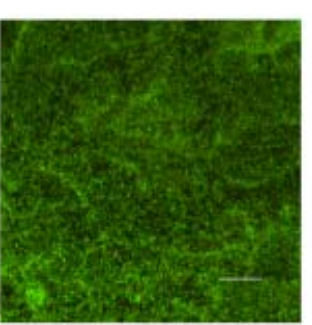

B

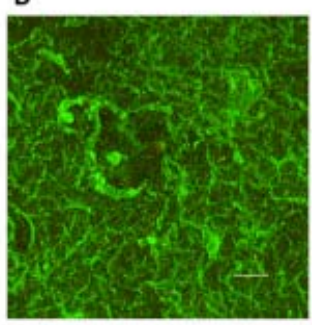

D

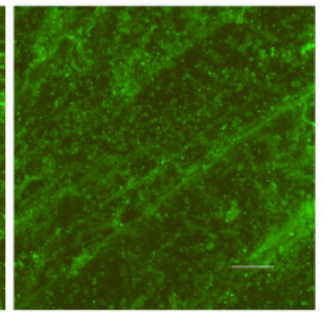

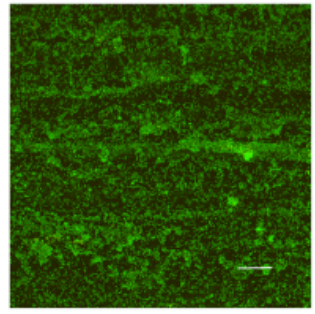
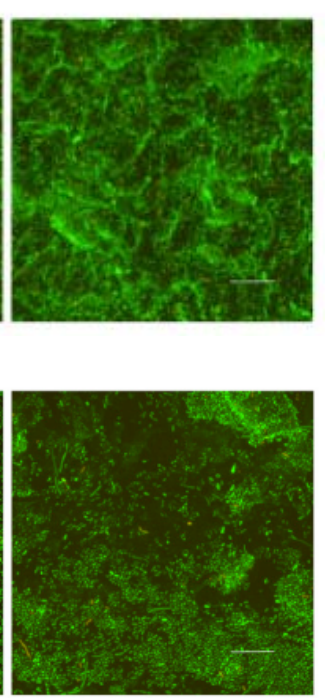

Fig. (2). CLSM images of biofilms on DBR disc surfaces. Biofilm formation of F. nucleatum ATCC 23726 (A) T. forsythia ATCC 43037 (B) V. atypica PK 1910 (C) K. pneumoniae IA 565 (D) on DBR discs. For each set, the image on the left was taken through a 20x objective (Scale bar, $50 \mu \mathrm{m}$ ); while the image on the right was taken through a 63x objective (Scale bar, $20 \mu \mathrm{m}$ ). Four random fields of view were examined for each sample and representative images are shown.

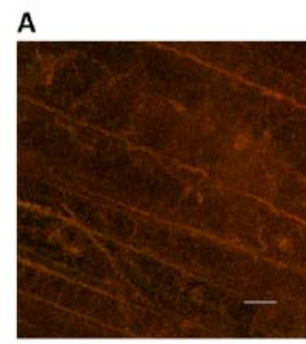

B

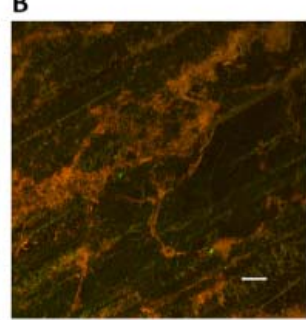

$\mathrm{E}$

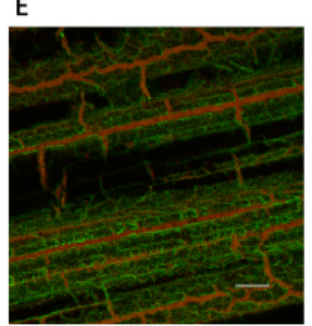

F

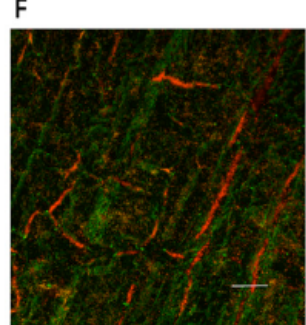

C

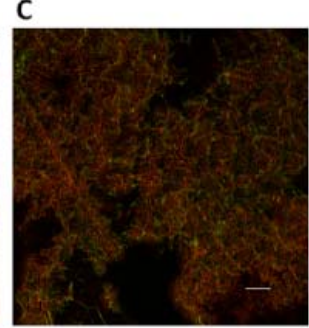

G

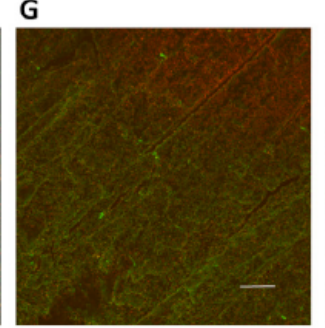

D

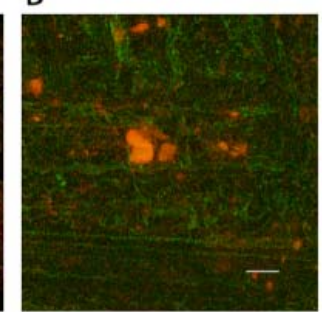

H

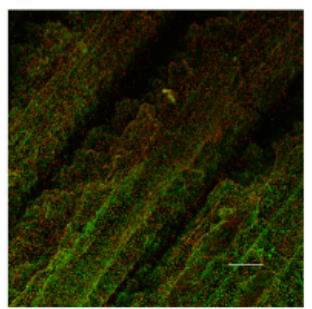

Fig. (3). CLSM images of $F$. nucleatum $(\mathbf{A}, \mathbf{E})$ T. forsythia $(\mathbf{B}, \mathbf{F}) V$. atypica $(\mathbf{C}, \mathbf{G}) K$. pneumoniae $(\mathbf{D}$, H) biofilms formed on DBR disc surfaces after treatment with Polident ${ }^{\circledR}$ experimental formulation M138-12 (upper panel) and Efferdent ${ }^{\circledR}$ (lower panel), respectively. Denture biofilms were stained with SYTO59 and SYTOX Green as described in Materials and Methods, and examined by CLSM to reveal the live (green) and dead (red) cell population following treatment. Four random fields of view were examined for each sample and representative images taken through a 20x objective are shown (Scale bar, $50 \mu \mathrm{m})$.

formula Polident ${ }^{\circledR}$ M138-12 or Efferdent ${ }^{\circledR}$ resulted in $10^{2}-10^{3}$ and $10^{3}-10^{4}$ surviving CFU, respectively (Fig. 4B). Quantitative values for killing efficacy were not determined for $V$. atypica and $T$. forsythia since CFU recovery on the recommended agar medium plates exhibited large variability under our experimental conditions.

Mono-species DBR-attached biofilms formed by halitosis-related bacterial species were used to evaluate the efficacy of denture cleansers. Biofilms were stained with SYTO59 and SYTOX Green and examined by CLSM to reveal the live/dead cell distribution following the different treatments as described in Material and Methods. Compared to PBS-treated mono-species denture biofilms in which the majority of the cells were alive, treatment with the experimental formula Polident ${ }^{\circledR}$ M138-12 almost completely killed the bacterial cells within mono-species biofilms formed on DBR discs by $F$. nucleatum, $T$. forsythia and $V$. atypica (Figs. 3A, 3B and 3C). In contrast, the same treatment of $K$. pneumoniae biofilms yielded less apparent killing (Fig. 3D). Treatment with Efferdent ${ }^{\circledR}$ did not result in complete killing of bacterial cells within any of the mono-species denture biofilms formed by $F$. nucleatum, T. forsythia, V. atypica, or $K$. pneumoniae within 5 min of treatment time (Figs. 3E, 3F, 3G and 3H). 


\section{A}

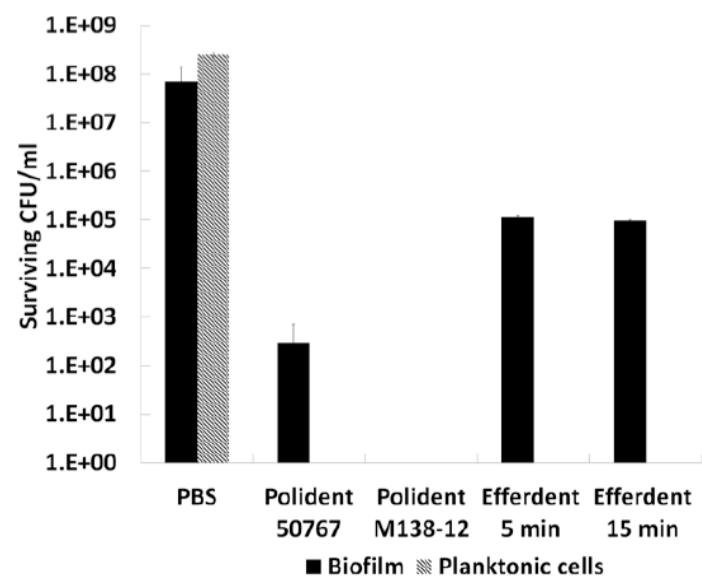

B

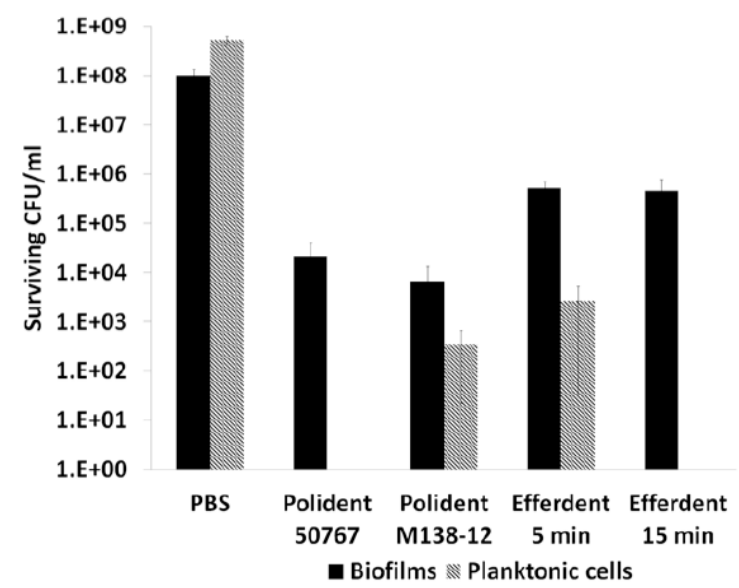

Fig. (4). Antimicrobial treatment efficacy against biofilms formed on DBR disc surfaces and planktonic cells. The biofilms and planktonic cells of $F$. nucleatum (A) and K. pneumoniae (B) were treated with denture cleansers as described in the Materials and Methods. The viability of biofilms after treatment was assessed by colony-forming units (CFU) on agar plates. Standard error of three replicates is presented.

\section{DISCUSSION}

Denture-related halitosis poses a serious problem, particularly for elderly denture-wearers [10]. The colonization of denture surfaces with odor-producing oral bacteria has been suspected to play an important role in causing dentureassociated halitosis [4, 9-11]. However, the ability of halitosis-related bacteria to colonize and form biofilms on denture surfaces remains poorly understood.

In this study, clinical denture plaque samples were screened for the presence of four selected oral bacterial species that have previously been implicated in halitosis and are known to produce malodorous compounds [3-7]. A high percentage of subjects contained at least one of these halitosisrelated species within their denture plaque, although no significant difference was observed between the stomatitis and healthy group (Table 1). The high prevalence of these halitosis-related microbes within denture plaques from both healthy (60\%) and denture stomatitis patients (80\%) suggested that these bacterial species were able to colonize denture surfaces and therefore could have biofilm-forming ability.

Our study further demonstrated that all four tested halitosis-related species were indeed capable of biofilm formation on the surface of discs manufactured from PMMA, the most commonly used denture material (Fig. 1). The ability to colonize and develop biofilms on denture surfaces not only enables these bacteria to exploit an additional growth niche; biofilms also provide an environment that is more protected against the host immune defense as well as other external stresses such as antimicrobial agents [20, 21]. In cases of poor oral hygiene, dentures could serve as a reservoir for these odor-producing bacteria and result in persistent halitosis.

Our result also revealed different biofilm formation abilities and various biofilm structures among the tested species, with $F$. nucleatum and $T$. forsythia exhibiting greater biofilm coverage of PMMA surfaces. This is consistent with our previous studies showing that different bacterial species displayed differential colonization of the same surfaces, and surfaces of different physical properties greatly affected the biofilm formation ability of the same bacterial strains [17].
The observed higher resistance of denture biofilm cells to Polident $^{\circledR}$ and Efferdent ${ }^{\circledR}$ antibacterial denture cleansers compared to their planktonic counterparts is not surprising, since biofilm cells are generally more resilient against external stresses including antimicrobial treatments (Fig. 4) [20]. This highlights the importance of testing antimicrobial activities against relevant biofilm cells rather than planktonic microbes. A variety of dental products, including denture cleansers, which often contain antimicrobial compounds, have been developed for treating denture-related halitosis by reducing or eliminating odor-producing bacteria [22]. Our study demonstrated the successful application of monospecies denture biofilm models for halitosis-related bacteria in evaluating the efficacy of such cleansers. Differential killing of mono-species biofilms of different species was observed for the same denture cleanser formula. Meanwhile, the three denture cleansers tested in this studies exhibited different killing efficacies when tested with the same bacterial species. Our findings confirm that these denture biofilm models can serve as a useful model system for screening and evaluation of dental products, particularly products for treating denture-related halitosis. Furthermore, the mono-species DBR biofilm model developed in this study could be expanded to establish a more clinically relevant multispecies halitosis-related biofilm model for dental product evaluation, as well as for pathogenesis studies of denture-related halitosis.

\section{CONCLUSION}

Four selected halitosis-related bacterial species were almost equally present in plaque isolated from healthy denture wearers as well as denture stomatitis patients in this study. Furthermore, the monospecies biofilm formation of these species on denture material discs was evaluated and the resulting model systems were successfully employed to test the antibacterial effectiveness of different denture cleansers.

\section{CONFLICT OF INTEREST}

The authors confirm that this article content has no conflict of interest. 


\section{ACKNOWLEDGEMENTS}

We thank Dr. Steven Clegg for providing the K. pneumoniae IA 565 strain and the West China Hospital of Stomatology for providing denture plaque samples. This study was partially supported by a grant (2010-024) from GlaxoSmithKline Consumer Healthcare, Weybridge, UK; the International Science and Technology Cooperation Program of China (2011DFA30940) and the National Basic Research Program of China (2011CB512108), China.

\section{ETHICAL APPROVAL}

Ethical Approval was given by the Institutional Review Board at the West China Hospital of Stomatology, China (IRB number: 2012-0004).

\section{REFERENCES}

[1] Rosing CK, Loesche W. Halitosis: an overview of epidemiology, etiology and clinical management. Braz Oral Res 2011; 25(5): 46671.

[2] Loesche WJ, Kazor C. Microbiology and treatment of halitosis. Periodontol 2002; 28: 256-79.

[3] Persson S, Edlund MB, Claesson R, Carlsson J. The formation of hydrogen sulfide and methyl mercaptan by oral bacteria. Oral Microbiol Immunol 1990; 5(4): 195-201.

[4] Goldberg S, Cardash H, Browning H, Sahly H, Rosenberg M. Isolation of Enterobacteriaceae from the mouth and potential association with malodor. J Dent Res 1997; 76(11): 1770-5.

[5] Washio J, Shimada Y, Yamada M, Sakamaki R, Takahashi N. Effects of $\mathrm{pH}$ and lactate on hydrogen sulfide production by oral Veillonella spp. Appl Environ Microbiol 2014; 80(14): 4184-8.

[6] Haraszthy VI, Zambon JJ, Sreenivasan PK, et al. Identification of oral bacterial species associated with halitosis. J Am Dent Assoc 2007; 138(8): 1113-20.

[7] Riggio MP, Lennon A, Rolph HJ, et al. Molecular identification of bacteria on the tongue dorsum of subjects with and without halitosis. Oral Dis 2008; 14(3): 251-8.

[8] Kazor CE, Mitchell PM, Lee AM, et al. Diversity of bacterial populations on the tongue dorsa of patients with halitosis and healthy patients. J Clin Microbiol 2003; 41(2): 558-63.
[9] Verran J. Malodour in denture wearers: an ill-defined problem. Oral Dis 2005; $11: 24-8$.

[10] Nalcaci R, Baran I. Factors associated with self-reported halitosis (SRH) and perceived taste disturbance (PTD) in elderly. Arch Gerontol Geriatr 2008; 46(3): 307-16.

[11] Baran I, Nalcaci R. Self-reported denture hygiene habits and oral tissue conditions of complete denture wearers. Arch Gerontol Geriatr 2009; 49(2): 237-41.

[12] Jeganathan S, Lin CC. Denture stomatitis: a review of the aetiology, diagnosis and management. Aust Dent J 1992; 37(2): 107-14.

[13] Liu Y, Liu C, Zheng W, et al. PCR detection of Klebsiella pneumoniae in infant formula based on 16S-23S internal transcribed spacer. Int J Food Microbiol 2008; 125(3): 230-5.

[14] Igarashi E, Kamaguchi A, Fujita M, Miyakawa H, Nakazawa F. Identification of oral species of the genus Veillonella by polymerase chain reaction. Oral Microbiol Immunol 2009; 24(4): 310-3.

[15] Kirakodu S.S, Govindaswami M, Novak MJ, Ebersole JL, Novak KF. Optimizing qPCR for the quantification of periodontal pathogens in a complex plaque biofilm. Open Dent J 2008; 2: 49-55.

[16] Sharma A, Sojar HT, Glurich I, Honma K, Kuramitsu HK, Genco RJ. Cloning, expression, and sequencing of a cell surface antigen containing a leucine-rich repeat motif from Bacteroides forsythus ATCC 43037. Infect Immun 1998; 66(12): 5703-10.

[17] Li L, Finnegan MB, Ozkan S, Kim Y, et al. In vitro study of biofilm formation and effectiveness of antimicrobial treatment on various dental material surfaces. Mol Oral Microbiol 2010; 25(6): 384-90.

[18] Sharma A, Inagaki S, Sigurdson W, Kurammitsu HK. Synergy between Tannerella forsythia and Fusobacterium nucleatum in biofilm formation. Oral Microbiol Immunol 2005; 20(1): 39-42.

[19] Francesco G, Ennio B, Claudio A, Francesco C, Marco C. Atomic force microscopy of bacteria from periodontal subgingival biofilm: preliminary study results. Eur J Dent 2013; 7(2): 152-8.

[20] Mah TF, O'Toole GA. Mechanisms of biofilm resistance to antimicrobial agents. Trends Microbiol 2001; 9(1): 34-9.

[21] Hall-Stoodley L, Stoodley P. Evolving concepts in biofilm infections. Cell Microbiol 2009; 11(7): 1034-43.

[22] De Oliveira VM, de Lucena SC, Garcia RC, Del Bel Cury AA. Effect of a denture cleanser on the concentration of volatile sulphur compounds and denture biofilm in institutionalized elderly. Gerodontology 2011; 28(2): 134-9.

Received: January 02, 2015

Revised: January 26, 2015

Accepted: February 24,2015

(C) Wu et al.; Licensee Bentham Open.

This is an open access article licensed under the terms of the Creative Commons Attribution Non-Commercial License (http://creativecommons.org/licenses/by-nc/3.0/) which permits unrestricted, non-commercial use, distribution and reproduction in any medium, provided the work is properly cited. 